\title{
Powdery Mildew Protection with Armurox: An Improved Strategy for Silicon Application
}

\author{
A. Botta, N. Sierras, C. Marín, M. Carrión and R. Piñol \\ Department of Research \& Development, Division of Plant Physiology, BIOIBERICA, S.A., Palafolls, Barcelona 08389, Spain
}

Received: April 8, 2011 / Published: November 20, 2011.

\begin{abstract}
Powdery mildew diseases cause severe losses in a wide variety of crop plants, for which no polyvalent fungicide measures are available for every disease situation. In addition, alternative treatments for plant disease protection have recently raised more interest due to restrictions and environmental concerns regarding the use of pesticides worldwide. This study was aimed at verify a new technology for integrated disease management strategies to protect crops against pathogenic fungi. Armurox ${ }^{\circledR}$, a formulation of specific peptide compounds with soluble silicon (Si), acts as an active barrier in preventing haustorial penetration and stimulating plant defense mechanisms when the pathogen appears. This mode of action was tested on different plant pathosystems and its field effectiveness evaluated on several fruit and horticultural crops, compared with most used chemical treatments. The peptide biocompatible coformulant promotes greater Si foliar uptake in comparison with mineral silicate, as can be concluded from leaf $\mathrm{Si}$ deposition analysis, which in turns enhances plant resistance to fungi attack.
\end{abstract}

Key words: Soluble silicon, powdery mildew, foliar application, induced resistance, biocompatible uptake enhancers.

\section{Introduction}

Control of powdery mildew under field conditions has become a chronic problem in a wide variety of agricultural crops. Although great economic investments have been made into genetic improvement programs, the application of fungicides continues to be the main tool for fighting pathogenic fungi diseases. The impact of chemical control, however, has been lessened by the pathogens' tendency to develop resistance, rendering many systemic fungicides ineffective [1]. Moreover, increasing legal limitations on the use of pesticides and public concern about the effects of chemical agents on the environment have led to a search for alternative or complementary control measures that are environmentally more acceptable than conventional pesticides.

One of the most interesting alternative strategies is

Corresponding author: A. Botta, M.Sc., research fields: plant physiology and pathology, plant stress management. E-mail: abotta@bioiberica.com. based on the use of plant defense inducers. Induced resistance is defined as increased resistance to pathogens and other biotic and abiotic stress factors following the recognition of the resistance-inducing agent [2]. Induced resistance can be triggered by treatments with a variety of biotic or abiotic inducers, such as nonpathogen microorganisms and inorganic compounds [3].

Silicon (Si) application has been reported to enhance many structural and biochemical components of resistance to several powdery mildew diseases in different crops, such as cucumber [4], wheat [5], strawberry [6] and grape [7]. Its benefits are described as a combination of both a $\mathrm{Si}$ deposition in the epidermal plant tissues to create a physical barrier to pathogen penetration and the enhancement of host defense responses $[8,9]$. For the prophylactic effect to be manifest, soluble Si needs to be absorbed by the plant, a process that has been extensively demonstrated to occur through the roots in some plants, but which takes place at a lower rate by foliar 
application [5].

Organic nitrogen compounds have been used as carriers or promoters to increase Si uptake in rice plants [10]. Biocompatible enhancers have also been shown to increase foliar absorption of other nutrients, such as calcium and potassium in different crops [11]. The aim of this study is to test the effectiveness of the new technology, Armurox, a formulation of active Si in a peptide solution, to improve Si absorption and enhance plant resistance to fungi diseases.

\section{Materials and Methods}

The present study was based on the verification of the agronomic effectiveness of Armurox ${ }^{\circledR}$ (Bioiberica, S.A.) as a powdery mildew control measure. For this purpose, several trials in different cultures susceptible to suffering the disease were carried out in Spain over a period of 4 years. First of all, dose-finding trials were conducted either on horticultural crops or fruit trees. Evaluation protocols for disease control were then established to adapt Armurox treatments according to each type of crop and disease sensitivity condition. In this case, results were compared with a non-treated plot and a standard chemical treatment using the Student-Newman-Keuls statistical test with a 95\% confidence level. Here we present a selection of 4 representative trials to evaluate product effectiveness according to Abbott's efficacy formula for pesticides [12].

\subsection{Dose-Finding Trial on Cucurbits}

Evaluation of the best dose of Armurox on melon cv. Galia (Cucumis melo L. cv. reticulatus) against powdery mildew of cucurbits (Podosphaera fusca (Fr.) Braun et Shishkoff) was carried out in Fuente Alamo, Murcia (southeast Spain). Seeds were sown on 30 March at a density of $2 \times 0.5 \mathrm{~m}^{2}$. Treatment plots were laid out as a randomized complete block design with 4 replications. The elemental plot was $20 \mathrm{~m}^{2}$ in size. Two doses of Armurox were tested: a low dose of 150 $\mathrm{mL} \mathrm{hL}^{-1}$ and a higher dose of $300 \mathrm{~mL} \mathrm{hL}^{-1}$, in a program consisting of 3 separated foliar applications (A, B \& C) with an interval of between 7 and 10 days. The first application took place on 26 June (phenological stage $\mathrm{BBCH}$ 83). For the foliar applications, a motorized backpack sprayer (Maruyama MD-07) was used at a pressure of $900 \mathrm{kPa}$. A total volume of 1,000 $\mathrm{L} \mathrm{ha}^{-1}$ was applied. Four evaluations were made to determine the percentage of leaves affected by the disease (\% Incidence) and the percentage of damaged leaf surface (\% Severity) on a sample of 25 leaves per plot. The evaluations were made just before the first treatment (0 DAT), 10 days after first treatment (10 DA-A), 7 days after second treatment (7 DA-B) and 7 days after third treatment (7 DA-C).

\subsection{Dose-Finding Trial on Stone Fruit Trees}

Evaluation of the best dose of Armurox on peach cv. Caterina (Prunus persica L.) against powdery mildew of stone fruits (Sphaerotheca pannosa (Wallr.) Lev. var. persicae Wor) was carried out in Cieza, Murcia (southeast Spain) on a plantation of 8 -year-old trees. The planting pattern was $5 \mathrm{~m} \times 4 \mathrm{~m}$. Treatment plots were laid out as a randomized complete block design with 4 replications. The elemental plot was $40 \mathrm{~m}^{2}$ in size. Two doses of Armurox were tested, a low dose of $150 \mathrm{~mL} \mathrm{hL}^{-1}$ and a higher dose of $300 \mathrm{~mL} \mathrm{hL}^{-1}$, in a program consisting of 3 foliar applications (A, B \& C) separated by an interval of 7 days. The first application took place on 9 July (phenological stage BBCH 85). For the foliar applications a motorized backpack sprayer (Maruyama MD-07) was used at a pressure of 1,200 kPa. A total volume of 1,000 $\mathrm{L} \mathrm{ha}^{-1}$ was applied. Four evaluations were made to determine the percentage of leaves affected by the disease (\% Incidence) and the percentage of damaged leaf surface (\% Severity) on a sample of 25 shoots per plot. The evaluations were made at the beginning of the trial (0 DAT) and 7 days after each treatment (7 DA-A, 7 DA-B and 7 DA-C). 


\subsection{Effectiveness Trial on Strawberry Plants}

Evaluation of Armurox protection effectiveness on strawberries cV. Candonga (Fragaria $\times$ ananassa) against powdery mildew of strawberries (Sphaerotheca macularis f. sp. fragariae) was carried out in Palos de la Frontera, Huelva (southwest Spain). Seedlings were transplanted on 10 October at a density of 60,000 plants per hectare. Treatment plots were laid out as a randomized complete block design with 3 replications. The elemental plot was $12 \mathrm{~m}^{2}$ in size. Armurox was applied at the rate of $500 \mathrm{~mL} \mathrm{hL}^{-1}$ in a program consisting of 5 foliar applications (A, B, C, D \& E) separated by an interval of 7 to 30 days. The first application took place on 19 February (phenological stage BBCH 61-85). For the foliar applications a motorized backpack sprayer (Maruyama MD-07) was used at a pressure of $600 \mathrm{kPa}$. A total volume of 1,000 $\mathrm{L} \mathrm{ha}^{-1}$ was applied. Eleven evaluations were made to determine the percentage of fruit affected by the disease (\% Incidence) on a sample of 20 fruits per plot. The evaluations were made at the beginning of the trial (0 DAT) and every 5-20 days during the trial period (5 DA-A, 8 DA-B, 11 DA-C, 0 DA-D, 8 DA-E and 28 DA-E).

\subsection{Effectiveness Trail on Grapes}

Evaluation of Armurox protection effectiveness on grapes cv. Tempranillo (Vitis vinifera L.) against powdery mildew of grape [Uncinula necator (Schw.) Burr.] was carried out in Cenizate, Albacete (central Spain) on a plantation of 8-year-old grapevines. The planting pattern was $3 \mathrm{~m} \times 3 \mathrm{~m}$. Treatment plots were laid out as a randomized complete block design with 4 replications. The elemental plot was $27 \mathrm{~m}^{2}$ in size. Armurox was applied at the rate of $500 \mathrm{~mL} \mathrm{hL}^{-1}$ in a program consisting of 3 foliar applications (A, B \& C) separated by an interval of 1 month approximately. The first application took place on 29 May (phenological stage BBCH 57). For the foliar applications a motorized backpack sprayer (Maruyama MD-07) was used at a pressure of $800 \mathrm{kPa}$.
A total volume of $1,000 \mathrm{~L} \mathrm{ha}^{-1}$ was applied. Three evaluations were made to determine the percentage of bunches affected by the disease (\% Incidence) on a sample of 25 bunches per plot. The evaluations were made 22 days after first treatment (22 DA-A), 3 days after second treatment (3 DA-B) and 49 days after third treatment (49 DA-C).

\subsection{Silicon Absorption Analysis}

In order to test Armurox as a source of $\mathrm{Si}$, an experiment on rice plants was conducted under controlled conditions. Si content was analyzed by determining the concentration and deposition of this element on leaf tissue after product spraying. Rice seeds from the lsi1 mutant (low silicon rice 1, deficient in active Si uptake) were sterilized in 10\% (v $\mathrm{v}^{-1}$ ) $\mathrm{NaOCl}$ for $1.5 \mathrm{~min}$, rinsed in sterilized water for 3 min and germinated on distilled water-soaked germitest paper (Fisher Scientific Co., Pittsburgh, PA) in a germination chamber at $25^{\circ} \mathrm{C}$ for 6 days. Germinated seedlings were transferred to plastic containers with a one-half-strength nutrient solution for two days. After this period, the plants were transferred to new plastic containers with a nutrient solution. The non-aerated nutrient solution was changed every two days. The $\mathrm{pH}$ was checked daily and kept at around 5.5 by using $\mathrm{NaOH}$ or $\mathrm{HCl}(1 \mathrm{M})$ when needed. The nutrient solution used in this study was prepared on the basis of Arnold \& Hoogland (1950), with some modifications. This nutrient solution was Si-free. The treatments for the experiment were: (i) plants sprayed with distilled water, (ii) plants sprayed with Armurox solution (5 $\mathrm{mL} \mathrm{L}^{-1}$ ) and (iii) plants sprayed with potassium silicate solution (2.1 $\mathrm{g} \mathrm{L}^{-1}$ ). Both Si treatments applied the same amount of Si. Leaves of plants at the second leaf tiller growth stage were sprayed until run-off occurred, using a VL Airbrush atomizer (Paasche Airbush Co., Chicago, IL). The base of the plant was covered when sprayed to prevent run-off into the nutrient solution. Leaves from the plants that received 
all the treatments were removed 24 hours after spraying. The leaves were gently washed in sterile deionized water for 10 minutes to potentially remove any Si deposited on the sprayed leaf surface, and then analyzed for Si concentration as described by Elliot \& Snyder (1991) [13] and by scanning electron microscopy, coupled to an energy dispersive X-ray microanalysis mapping. The experiment was arranged in a completely randomized design with five replications. Each experimental unit consisted of one plastic container with $5 \mathrm{~L}$ of nutrient solution and 4 rice plants. Data for Si concentration on leaf tissue and also from X-ray microanalysis were subjected to ANOVA and means were tested for significant differences $(P=0.05)$ using Tukey’s test.

\section{Results}

\subsection{Melon Trial Results}

Environmental conditions were optimal for powdery mildew development. This became evident at the end of the experiment from the incidence value on untreated melon plants, which reached 100\% (data not shown). In addition, severity was superior to $50 \%$ in the control plants. During the whole of the trial period, severity results of Armurox treatments showed statistically significant disease reduction compared to the control plot. No differences between the tested product doses were observed. Nevertheless, at the higher dose, Armurox showed a tendency to have a greater effect (Fig. 1a). Effectiveness of the higher dose of Armurox computed by Abbott's formula remained above $50 \%$ throughout the whole of the trial period (Fig. 1b).

\subsection{Peach Trial Results}

Powdery mildew attack was also intense in the peach trial where the untreated plot reached an incidence of $91 \%$ by the end of the study (data not shown). Attack severity was reduced with the application of both doses of Armurox (Fig. 2a), with the higher dose being significantly more effective. This effectiveness of the high dose remained at around $70 \%$ at all of the evaluation points (Fig. 2b).

\subsection{Strawberry Trial Results}

The number of strawberry fruit affected by powdery mildew was evaluated in this trial. Fungus disease was present from the beginning and fluctuated throughout the trial period with a maximum incidence peak of $47 \%$ in the control plot. Both treatments showed very good performance in controlling powdery mildew (Fig. 3a). The effectiveness of the Armurox treatment was comparable at all times to the comprehensive Spray Farmer Program (SFP), consisting of an alternate application of several active ingredients (Cyprodinil + Fludioxonil / Myclobutanil / Potassium phosphite / Penconazole / Fenhexamid) (Fig. 3b).

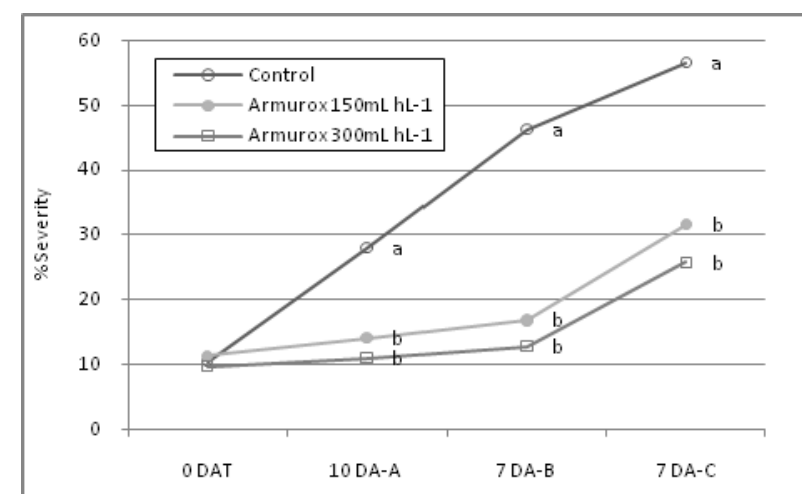

(a)

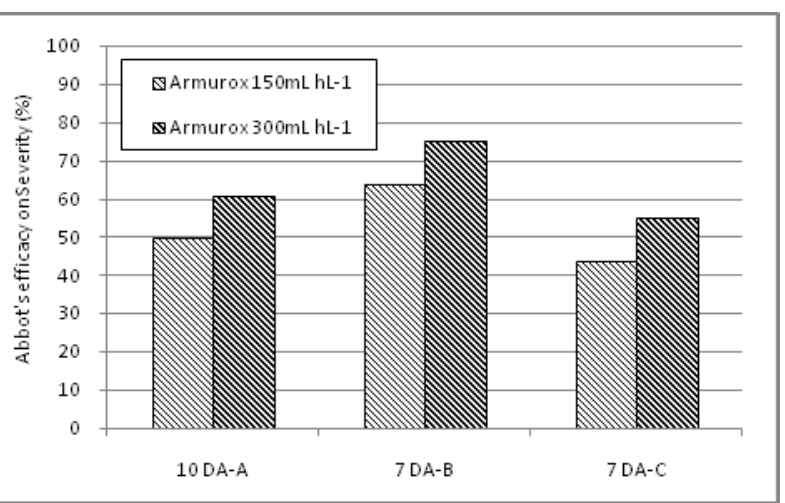

(b)

Fig. 1 (a) Area damaged on melon leaves (\% Severity) at different evaluation points: 0 days after treatment (0 DAT), 10 days after first (A) treatment (10 DA-A), 7 days after second (B) treatment (7 DA-B) and 7 days after third (C) treatment (7 DA-C). (b) Abbott's efficacy on Severity (\%) at the different evaluation points. 


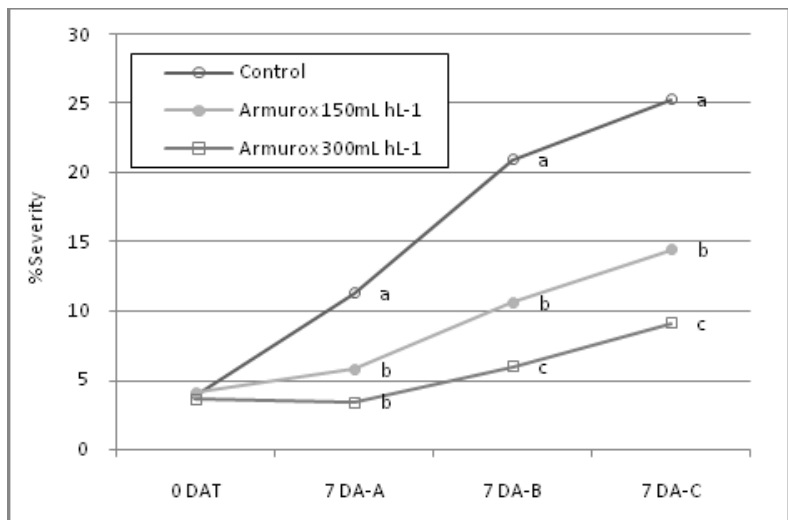

(a)

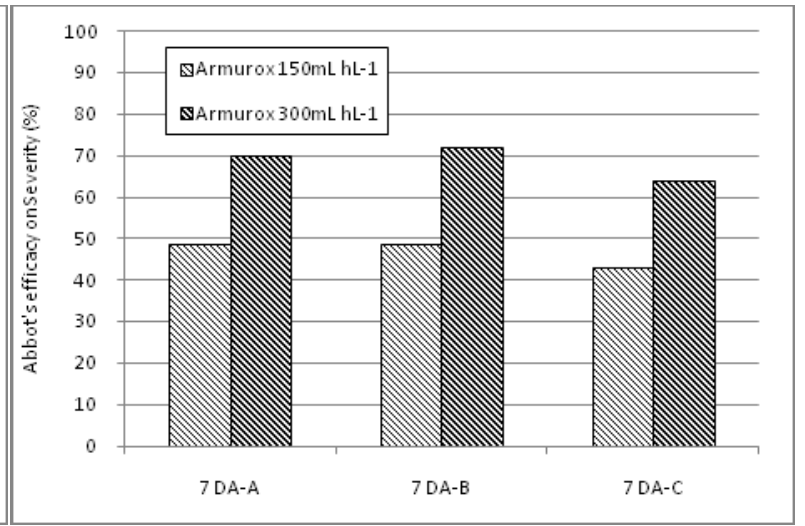

(b)

Fig. 2 (a) Area damaged on peach leaves (\% Severity) at different evaluation points: 0 days after treatment (0 DAT), 7 days after first (A) treatment (7 DA-A), 7 days after second (B) treatment (7 DA-B) and 7 days after third (C) treatment (7 DA-C). (b) Abbott's efficacy on Severity (\%) at the different evaluation points.

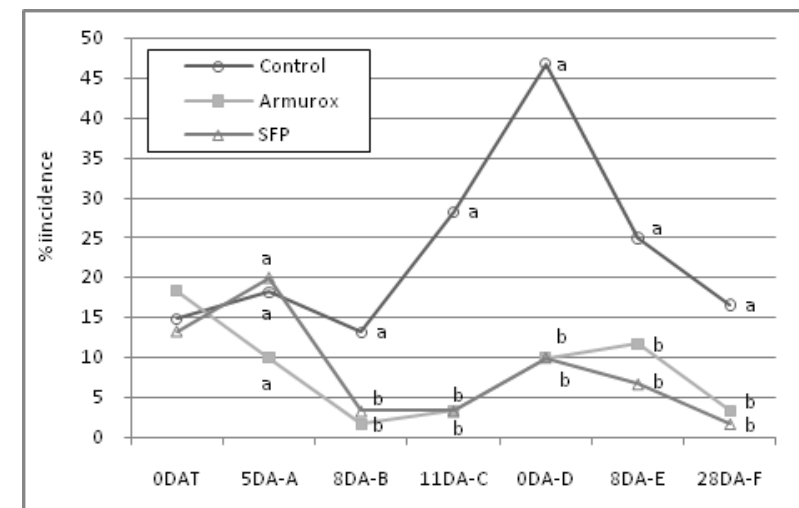

(a)

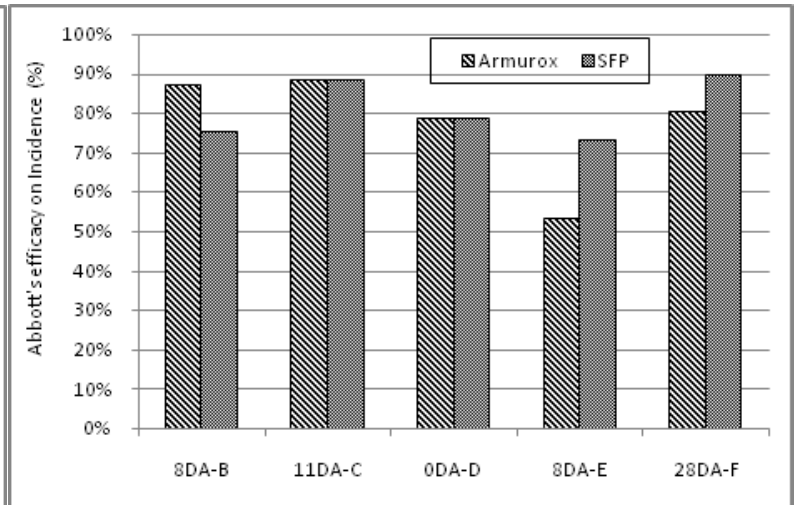

(b)

Fig. 3 (a) Percentage of strawberry leaves affected by the disease (\% Incidence) at different evaluation points: 0 days after treatment (0 DAT), 5 days after first (A) treatment (5DA-A), 8 days after second (B) treatment (8 DA-B), 11 days after third (C) treatment (11 DA-C), 0 days after fourth (D) treatment (0 DA-D), 8 days after fifth (E) treatment (8 DA-E) and 28 days after last (F) treatment (28 DA-F). (b) Abbott's efficacy on Incidence (\%) at the different evaluation points.

\subsection{Grape Trial Results}

This trial tested the effectiveness of Armurox in controlling powdery mildew in grape for wine production. The "Tempranillo" variety is one of the most cultivated varieties in Spain and is attacked almost every year by powdery mildew. The incidence of the disease in bunches was around 25\% in the control plot (Fig. 4a). From the second application, treated vines were significantly different compared to control vines (Fig. 4a). At the end of the trial, both Armurox and the Spray Farmer Program (Sulfur 80\% WP) demonstrated great effectiveness in controlling the disease. This was especially significant in the case of Armurox, which reached $100 \%$ of protection against powdery mildew (Fig. 4b).

\subsection{Silicon Absorption Analysis}

The Si concentrations in rice plant leaves sprayed with Armurox or potassium silicate were significantly increased ( $P \leq 0.05$ ) by $72.2 \%$ and $50 \%$ respectively in comparison to plants sprayed with distilled water (Table 1). However, the Si deposition in rice plant leaves sprayed with Armurox increased significantly $(P \leq 0.05)$ in comparison to the other two treatments based on both weight and atomic variables (Table 1). Data from both weight and atomic variables were obtained from spectra generated from the energy dispersive X-ray analyses of leaf samples obtained from each treatment. 


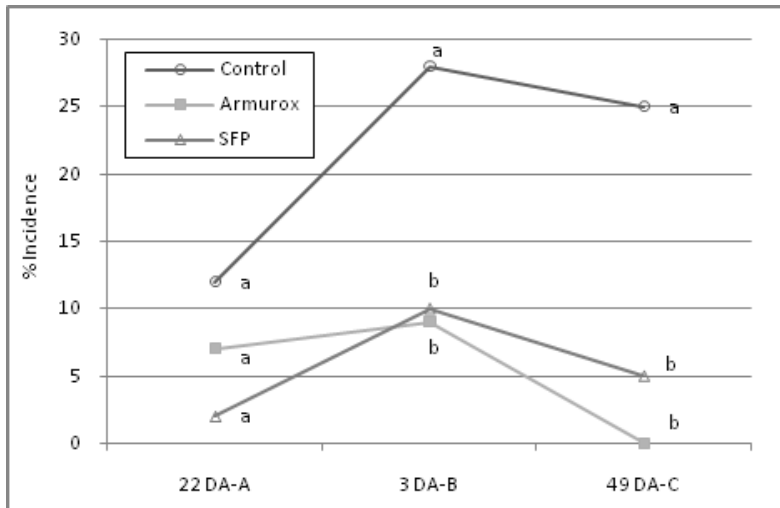

(a)

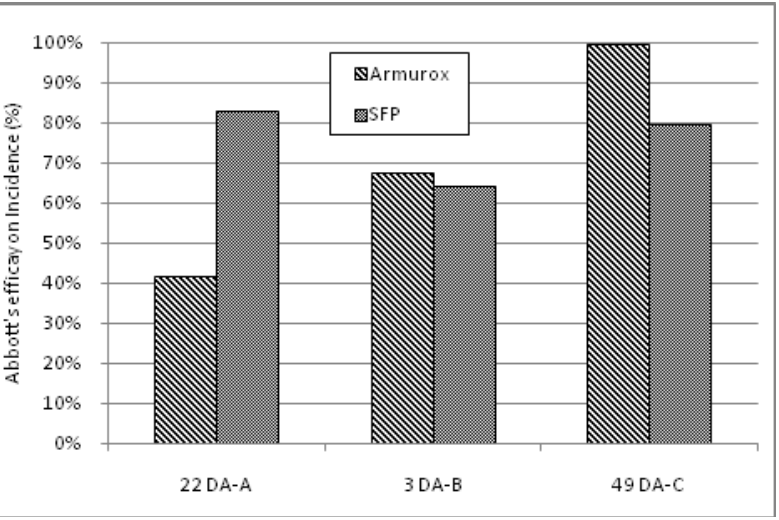

(b)

Fig. 4 (a) Percentage of grape leaves affected by the disease (\% Incidence) at different evaluation points: 22 days after first (A) treatment (22 DA-A), 3 days after second (B) treatment (3 DA-B) and 49 days after third (C) treatment. (b) Abbott's efficacy on Incidence (\%) at the different evaluation points.

Table 1 Silicon concentration (\% $\mathrm{Si}$ ) and $\mathrm{Si}$ deposition (Weight \% \& Atomic \%), determined by $\mathrm{X}$-ray analysis, in rice plant leaves subjected to different treatments.

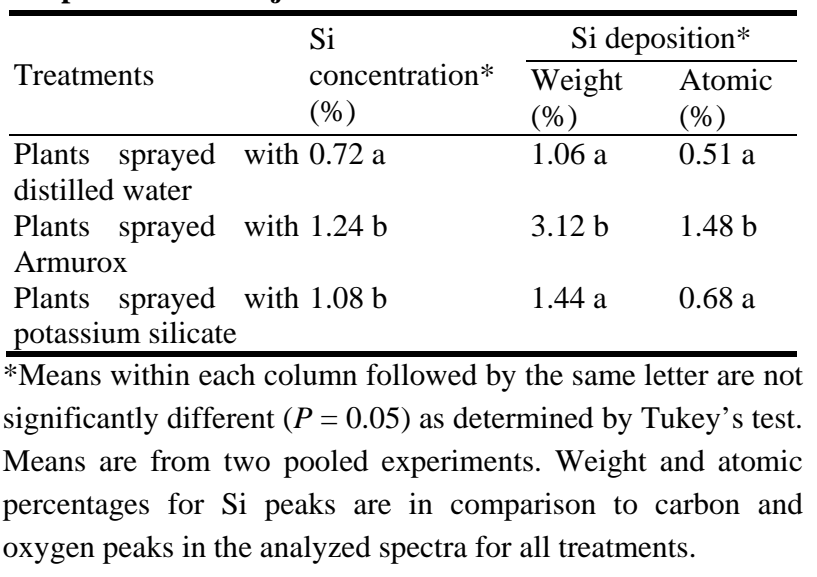

\section{Discussion}

\subsection{Dose-Finding Trials}

All the trials were performed on commercial agricultural parcels under conditions of natural inoculum in the field. The results of the dose trials confirmed that it is necessary to apply the treatment several times, with short intervals between applications (7-10 days) for proper disease control. In Cucurbits, powdery mildew can be caused by several species, but in numerous samplings in southern Spain over the past 30 years it has only been attributed to $P$. fusca as the causal agent. It is controlled mainly by means of fungicides, which entails a considerable economic cost in addition to a negative environmental impact [14]. In the melon trial, Armurox is able to significantly reduce the severity of fungus attack. The tendency is to a better effect when increasing the product concentration to $300 \mathrm{~mL} \mathrm{hL}^{-1}$. In the case of stone fruits, powdery mildew is controlled by fungicides but resistance is developing, so a strategy integrating the use of alternative treatments along with fungicides from different classes is recommended [15]. In the Peach trial, the product is effective in reducing the disease from the first application. Dosing at 300

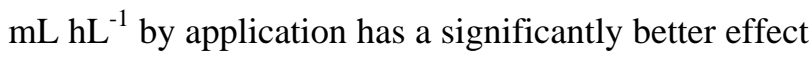
than $150 \mathrm{~mL} \mathrm{hL}^{-1}$. Therefore, it is confirmed that there is a dose-response effect. In general, for an effective reduction of the disease, dosing at $300 \mathrm{~mL} \mathrm{hL}^{-1}$ - the minimum product concentration - is recommended for any culture. On the other hand, although effectiveness is obtained from the first application, both in horticultural crops and fruit trees it is better to establish an application program of Armurox. According to these experiences, it can be established to initiate applications from the first symptoms of the disease or prior to the appearance of the fungus if possible.

\subsection{Effectiveness Trails}

With regard to the effectiveness trials, Armurox was tested on strawberries, where powdery mildew is one of the main problems for this culture. In Spain, as 
in other European countries, most strawberries are produced under covered systems, a humid environment which is highly favorable to pathogen development [16]. In addition to that, weather conditions were very humid in the strawberry trial, increasing the criticality of this factor during the experiment. Consequently, it was necessary to increase the number of applications in this trial, since the fruit loses commercial value when affected. The application of Armurox could hinder and reduce the development of the disease throughout the culture cycle. Armurox was found to have a good effectiveness of protection, similar to the alternate combination of chemical active ingredients that the farmer used. Finally, in the case of the grapevines, Armurox's effectiveness increased with each application. With the three applications, Armurox was able to completely reduce the symptoms of the disease, being a better option in comparison to the standard used by the farmer. In the case of grapes for wine production, it is important that they reach the end of the ripening period in a good sanitary state. Nevertheless, to not affect the subsequent fermentation process and the quality of the wine, the use of fungicides during a safety period before harvesting is not advised [17]. In this sense, Armurox can be a good alternative for the farmer in handling powdery mildew in grape.

\subsection{Silicon Absorption Trial}

In the test of rice under controlled conditions, two different formulations of $\mathrm{Si}$, Armurox and potassium silicate were compared through foliar application. With regard to Si uptake rate, it was found that the peptide component of Armurox helped achieve a superior rate of absorption and deposition of $\mathrm{Si}$ in comparison to mineral silicate. Si deposition in plant leaves has been related to the prevention of mildew conidia penetration [18]. Consequently, a reduction in powdery mildew development with Si feeding plants has already been reported [19].

\section{Conclusions}

The results on both horticultural crops and fruit trees indicate that the application of Armurox can be an effective alternative or a complementary measure to the intensive use of fungicides for addressing powdery mildew worldwide. The formulation of peptide uptake enhancers and soluble $\mathrm{Si}$ in the one product works together in synergy to enhance plant resistance to fungi infections. In this sense, Armurox provides a new technology for integrated disease management strategies to reduce fungicide applications and minimize chemical residues in crops. Although Armurox has been shown to be effective in commercial fields, further tests should be conducted to evaluate a possible induced resistance effect in host plants in addition to the Si deposition barrier when Armurox is applied.

\section{References}

[1] F. López-Ruiz, A. Pérez-García, D. Fernández-Ortuño, D. Romero, E. García, A. De Vicente, et al., Sensitivities to DMI fungicides in populations of Podosphaera fusca in south central Spain, Pest Management Science 66 (2010) 801-808.

[2] L. Faessel, N. Nassr, T. Lebeau, B. Walter, Effects of the plant defence inducer, acibenzolar-S-methyl, on hypocotyls rot of soybean caused by Rhizoctonia solani AG-4, Journal of Phytopathology 156 (2008) 236-242.

[3] D. Walters, D. Walsh, A. Newton, G. Lyon, Induced resistance for plant disease control: maximizing the efficacy of resistance elicitors, Phytopathology 95 (2005) 1368-1373.

[4] Y.C. Liang, W.C. Sun, J. Si, V. Römheld, Effects of foliar- and root-applied silicon on the enhancement of induced resistance to powdery mildew in Cucumis sativus, Plant Pathology 54 (2005) 678-685.

[5] M.H. Guével, J.G. Menzies, R.R. Bélanger, Effect of root and foliar applications of soluble silicon on powdery mildew control and growth of wheat plants, European Journal of Plant Pathology 119 (2007) 429-436.

[6] T. Kanto, M. Kazumasa, M. Aino, Suppression of conidial germination and appressorial formation by silicate treatment in powdery mildew of strawberry, Journal of General Plant Pathology 73 (2007) 1-7.

[7] P.A. Bowen, J.G. Menzies, D.L. Ehret, Soluble silicon sprays inhibit powdery mildews development on grape leaves, Journal of American Society of Horticultural 
Science 117 (1992) 906-912.

[8] F.Á. Rodrigues, W.M. Jurick II, L.E. Datnoff, J.B. Jones, J.A. Rollins, Silicon influences cytological and molecular events in compatible and incompatible rice-Magnaporthe grisea interactions, Physiological and Molecular Plant Pathology 66 (2005) 144-159.

[9] J.F. Ma, N. Yamaji, Silicon uptake and accumulation on higher plants, Trends in Plant Science 11 (2006) 392-397.

[10] S.R. Voleti, A.P. Padmakumari, V.S. Raju, S.M. Babu, S. Ranganathan, Effect of silicon solubilizers on silica transportation, induced pest and disease resistance in rice (Oryza sativa L.), Crop Protection 27 (2008) 1398-1402.

[11] A. Botta, C. Brigando, C. Marín, N. Sierras, M. Carrión, R. Piñol, Improved quality parameters in peach trees and raspberries by the addition of $\mathrm{Ca}$ or $\mathrm{K}$ with amino acids, Actas de Horticultura 49 (2007) 187-194.

[12] W.S. Abbott, A method of computing the effectiveness of an insecticide, Journal of Economic Entomology 18 (1925) 265-267.

[13] C.L. Elliot, G.H. Snyder, Autoclaved-induced digestion for the colorimetric determination of silicon in rice straw, Journal of Agricultural and Food Chemistry 39 (1991) 1118-1119.

[14] J.A. Torés, A. de Vicente, A. Pérez-García, Powdery mildew of cucurbits, in: R.M. Jiménez Díaz, E. Montesinos Seguí (Eds.), Diseases of Plants Caused by Fungi and Oomycetes, Nature and Integrated Control, Phytoma, Spain, 2010, pp. 251-252.

[15] A.P. Sholberg, F. Kappel, Integrated management of stone fruit diseases, in: A. Ciancio, K.G. Mukerji (Eds.), Integrated Management of Diseases Caused by Fungi, Phytoplasma and Bacteria, Springer, Netherlands, 2008, p. 3.

[16] Peries, Studies on strawberry powdery mildew, caused by Sphaerotheca macularis (Wallr. Ex Fries) Jaczewski, Annals of Applied Biology 50 (1962) 225-233.

[17] G. Barrios, VINE: powdery mildew, in: E. Martínez, G. Barrios, L. Rovesti, R. Santos (Eds.), Integrated Pest Management. Grup Bou, Tarragona, Spain, 2007, pp. 365-366.

[18] A.L. Samuels, A.D.M. Glass, D.L. Ehret, J.G.M. Menzies, Mobility and deposition of silicon in cucumber plants, Plant, Cell and Environment 14 (1991) 485-492.

[19] J.G. Menzies, D.L. Ehret, A.D.M. Glass, T. Helmer, C. Koch, F. Seywerd, The effects of soluble silicon on the parasitic fitness of Sphaerotheca fuliginea (Schlecht.: Fr.) Poll. on Cucumis sativus L., Phytopathology 81 (1991) 84-88. 